Dicenda. Estudios de lengua y literatura españolas

ISSN-e: $1988-2556$

http://dx.doi.org/10.5209/DICE.62146

\title{
Elementos narrativos del texto dramático
}

\author{
María Soledad Gómez Ruiz
}

Recibido: 25 de enero de 2016 / Aceptado: 29 de mayo de 2018

Resumen. En este artículo se estudia la importancia de lo narrativo en la nueva dramaturgia. Al parecer, uno de los caminos más transitados del teatro desde finales del siglo XIX es su concurrida narrativización, como afirma García Barrientos. La tradición se instaura después con el concepto de "epización" brechtiano y, como alternativa a esta novelización y epización, J. P. Sarrazac plantea el concepto de "rapsodia". Los autores contemporáneos exploran los límites de la narratividad en la nueva dramaturgia. Por otra parte, la dramaturgia vuelve siempre a sus orígenes y a enriquecerse de formas narrativas o líricas. En pleno siglo XXI los géneros se fusionan y contaminan más que nunca.

Palabras clave: adaptación teatral; narrativización del drama; epización; rapsodia.

\section{[en] Narrative elements of the dramatic text}

\begin{abstract}
In this article we study the narrative elements of the dramatic text give way to the importance of narrative in the new drama. Apparently, one of the busiest roads of the theatre since the late nineteenth century is its busy narrativization, as Garcia Barrientos says. The tradition then introduces the concept of Brechtian "epicisation" and, as an alternative to this novelization and epicisation, J. P. Sarrazac raises the concept of "rhapsody". Contemporary authors explore the limits of narrative in the new drama. Moreover, dramaturgy is forever predramatical for it returns to its origins and rich narrative or lyrical forms. In the XXI century genres merge and pollute more than ever.
\end{abstract}

Keywords: theatrical adaptation; narrativization of drama; epicisation; rhapsody.

Cómo citar: Gómez Ruiz, M. S. (2018). Elementos narrativos del texto dramático, en Dicenda. Estudios de Lengua y Literatura Españolas, 36, 253-265.

La adaptación teatral de textos narrativos es la práctica dramatúrgica más frecuente en nuestros días. El motivo de estas continuas adaptaciones puede ser que una de las señas de identidad del teatro actual sea su mestizaje. Sin embargo, ese rasgo no es nuevo puesto que el género teatral es de los más derivados temáticamente. Desde Grecia se reescriben y adaptan mitos, historias sagradas y profanas, novelas, cuentos, leyendas, etc. Por otra parte, el Romanticismo ha favorecido estas interferencias y mezclas de los géneros; Víctor Hugo (1827: 66-68) ensalza el drama y lo convierte en símbolo de la modernidad: "Solo el drama es poesía completa, pues encierra y resume la oda y la epopeya... Toda la poesía moderna desemboca en el drama". Esa fusión de los géneros literarios tiene que ver con la importante evolución de la novela y las genialidades individuales que preconizan una apertura revitalizadora de los

\footnotetext{
$1 \quad$ Universidad Complutense de Madrid soledadgomez@ucm.es
} 
mismos; basta leer La Celestina, El Quijote o La Divina Comedia para comprender el camino iniciado por la novela. Afirma García Barrientos (2004: 509-522) que, a finales del siglo XIX, uno de los caminos más concurridos de la dramaturgia es su progresiva narrativización, lo cual no impide que las fronteras entre una y otra modalidad de ficción sigan siendo particularmente nítidas desde la distinción aristotélica. Pérez Galdós sería en España el primer exponente de esa narrativización, pero también se puede hablar de dramatización de la narrativa a partir de Valle-Inclán. El autor plantea un interesante recorrido desde finales del XIX con la crisis del drama y su renovación a partir de Ibsen, Chéjov, Strindberg, Maeterlinck, Hauptmann y las búsquedas incesantes desde el naturalismo, simbolismo, expresionismo y el teatro épico a través del monólogo interior, el acto único y un largo etcétera que explica un gran cambio en la concepción del teatro contemporáneo. El texto dramático deja de ser convencional, causal o lineal al contar una historia con el planteamiento, nudo y desenlace. El drama moderno se caracteriza por la búsqueda incesante de una forma que se ajuste a la nueva manera de percibir la realidad, tendencia que ha de verse como un cambio en la relación entre el ser humano y el mundo. El individuo se ha separado de sí mismo, de los demás, de Dios, de la sociedad y de su propio presente. Peter Szondi explica ese cambio histórico en su Teoría del drama moderno (1956) a partir de lo que él define como "drama". El término se contamina o abre en el siglo XX hacia lo que entendemos por "épico" y esto significa, dicho con sus palabras (1956: 16), que el teatro "recoge el rasgo estructural común a la epopeya, el relato, la novela y otros géneros, consistente en la presencia de lo que ha dado en designarse como "sujeto de la forma épica o el yo épico". Sin embargo, el dramaturgo y teórico teatral, Jean-Pierre Sarrazac, aunque se reconoce deudor de Szondi, hace una lectura crítica sobre sus planteamientos en su libro L'avenir du drame (1999). En primer término, la transformación del drama ha sido teorizada por Mijail Bajtín que afirma la progresiva "novelización del drama" desde la década de los años ochenta del siglo XIX; después, con Brecht, se instaura el concepto de "epización" del teatro. Sarrazac es reticente a estas teorías y persiste, después de veinte años, en su denominación de "rapsodia" como alternativa a la novelización y la epización. En el comentario final del libro, un ensayo escrito para la segunda edición del texto titulado "El drama en devenir" (2009: 7) define en qué consiste la pulsión rapsódica:

La pulsión rapsódica - que no significa ni abolición ni neutralización de lo dramático (esa irreemplazable relación inmediata de sí al otro, el encuentro siempre catastrófico con el Otro que constituyen el privilegio del teatro)- procede en efecto por un juego múltiple de aposiciones y oposiciones de modos: dramático, lírico, épico, incluso argumentativo; de tonos, o de eso que se llama "géneros": farsesco y trágico, grotesco y patético, etcétera (eso que hace que Stein subtitule "su" Cerisaie "tragedia, comedia, pastoral, farsa", reencontrando así el sentido musical de composición libre de la rapsodia).

Este devenir rapsódico comienza, según el autor, en las grandes dramaturgias de finales del XIX y principios del XX, en el sentido de dar prioridad al monólogo y huir poco a poco del diálogo. Esta transformación no significa un agotamiento de la forma dramática sino al contrario: huir del diálogo no es abandonarlo sino enriquecer la escena de fragmentos literarios y abrir lo dramático hacia la forma más libre. Retomando el hilo sobre la teoría de Szondi, el autor, al hablar de esa escisión en la 
relación hombre y mundo, traduce para el teatro la separación entre sujeto y objeto, como recuerda Sarrazac (2013: 23) "esta síntesis dialéctica de lo objetivo (lo épico) y de lo subjetivo (lo lírico) que llevaba a cabo el estilo dramático -interiorizada exteriorizada, exteriorizada interiorizada- ya no es posible". Asimismo el autor afirma que le parece poco convincente Szondi en el análisis dramatúrgico de la obra de Ibsen, Strindberg y Pirandello y que su prejuicio a favor del "todo épico" vela lo más profundo y la aportación maestra de cada uno. Sarrazac opta por la noción de "autor rapsoda" como aquel que "cose o ajusta cantos" (2013: 191). Dicha noción aparece vinculada a lo épico, a los cantos y narraciones de Homero y hoy consiste en un procedimiento de escritura que incluye montaje, collage, remiendo, coralidad e hibridación. La rapsodia se caracteriza por un rechazo hacia la forma clásica aristotélica y una operación de descomposición y recomposición que confronta al escritor contemporáneo con un nuevo "texto-tejido". El autor lo expresa así (2013:192):

rechazo de la metáfora del "bello animal" aristotélico; caleidoscopio de los modos dramático, épico y lírico; reversión constante de lo alto y de lo bajo, de lo trágico y de lo cómico, ensamblaje de formas teatrales y extra-teatrales, que forman el mosaico de una escritura que es resultado de un montaje dinámico, atravesada por una voz narrativa e interrogadora, y desdoblamiento de una subjetividad alternativamente dramática y épica (o visionaria).

En suma, lo que instaura es un teatro en perpetua búsqueda y creo que coincide con el planteamiento de Sanchis Sinisterra. Para concluir esta reflexión sobre la rapsodia, quiero destacar al dramaturgo mexicano Édgar Chías, porque creo que se aplica con gran talento a la narración escénica. De hecho denomina Rapsodias para la escena (2010) al volumen que incluye tres obras (Telefonemas, El cielo en la piel y En las montañas azules). Telefonemas es una dramaturgia compleja que presenta varios tipos de discurso y supone el primer acercamiento del autor al arte del actorrapsoda. La obra editada en Argentina en 2004 fue finalista del Premio Nacional de Dramaturgia Manuel Herrera en 2001. Se trata, aparentemente de un diálogo entre los personajes principales, Ulises y Wanda, aunque también aparecen secundarios como Normita, el socio, un agente, etc. Las acotaciones explícitas son mínimas, al comienzo del texto hay una que propone la fusión de lo narrativo y lo dramático y advierte al lector que el texto plantea varias voces (al mismo tiempo): la del personaje, la del narrador y, por último, el analista. Las didascalias se escriben en letra cursiva para estimular la imaginación del lector y el dramaturgo presenta a dos personajes principales y sugiere que los otros, descritos con alguna característica, pueden ser encarnados según la imaginación del lector, pues toda la acción transcurre en la mente de Ulises. Creo más bien que por la dificultad actoral que propone el autor, son necesarios varios actores. También la estructuración de la obra parece imitar los capítulos de una novela corta o de un cuento (porque tiene un final impactante); se trata de doce secuencias (más la cero) con un título que presenta lo que va a acontecer al protagonista. La acción es progresiva, la dificultad consiste en que lo que ocurre en escena es producto de la mente de Ulises; hay una alternancia entre lo real y lo fantástico: la duda de si es sueño o realidad y el tema del doble se inserta poco a poco en el texto, como en los mejores relatos, hasta que suplanta la vida de Ulises, el otro Ulises. El discurso contiene narración fragmentada por ambos protagonistas, diálogo dramático, apartes, apelación al público, didascalias propias y ajenas, monó- 
logos. El texto apuesta por un actor que hace de todo en escena, la fusión de géneros se consigue y alternan de forma inteligente y vertiginosa.

Por otra parte, García Barrientos destaca el estudio de Ángel Abuín titulado El narrador en el teatro (1997), que amplía el recorrido hasta la segunda mitad del XX y el teatro Noh japonés con obras de autores como Paul Claudel, Alfonso Sastre, Tennessee Williams, Antonio Buero Vallejo, etc, que sirven como ejemplos de esta progresiva incursión de la mediación narrativa en el discurso teatral. También destaca el trabajo de Bobes Naves (1985) sobre Valle-Inclán, en el que la autora confronta el drama Sacrilegio con dos partes de su novela La corte de los milagros, donde aparece la misma estética, personajes y acciones, lo que demuestra el intento de aproximar la novela al teatro por parte del genial dramaturgo. Por último, es necesario subrayar el punto de vista creativo de José Sanchis Sinisterra en su especialidad sobre la teatralización de textos narrativos. Se trata del dramaturgo más influyente en la actualidad y el que más ha experimentado hasta ahora sobre las fronteras entre dramaticidad y narratividad. En el libro Dramaturgia de textos narrativos (2003) el autor expone dos ámbitos de adaptación: el de la relación entre narración oral y relato escrito y la distinción entre dramaturgia fabular, discursiva y mixta.

Como se puede constatar, desde los años 80 hasta la actualidad se han multiplicado las escrituras de desmontaje o la deconstrucción, los dramaturgos del nuevo milenio se caracterizan por una experimentación basada en la fragmentación. El objetivo común de la escritura dramática es inducir a los espectadores a colaborar activamente en la construcción del sentido. La narrativización del drama es una forma de contaminación enriquecedora; el arte como espejo del mundo muestra una sociedad cada vez más mestiza. Se puede hablar de "dramaturgia del mestizaje" como una forma de supervivencia, de contaminación múltiple frente a la globalización que a todos nos iguala. Carles Batlle (2008: 11-16) destaca a una serie de autores contemporáneos que exploran los límites de la narratividad, la esencia del diálogo o la mixtura de lo poético y lo cotidiano a partir de ese "choque de culturas". En la década de los ochenta, el pionero parece ser Bernard-Marie Koltés, al hablar de marginalidad, del miedo a la diferencia, del colonialismo, en obras como Muelle oeste, Combate de negro y perros o De noche justo antes de los bosques con una renovadora forma de expresión dramática. Destaca en la actualidad, el dramaturgo alemán Roland Schimmelpfennig; su obra más conocida, La noche árabe (Die nacht arabische) es una historia contada en cinco monólogos intercalados, los puntos de vista se entrelazan al convivir los personajes en el mismo edificio de una ciudad alemana. El juego entre realidad y ficción se plantea sutilmente al romper la cotidianeidad con el elemento onírico, así "el edificio se transforma en un escenario de motivos de Las mil y una noches y todos se ven sumergidos en un doble presente escindido entre Arabia y Alemania", como afirma Agostina Salvaggio (2009: 239). La acción transcurre en el apartamento de Fátima y Franciska, lugar que ejerce una atracción irresistible para Karpati, Lomeier y Kalil hasta el punto de transformar la vida normal del edificio en un viaje mágico que cambia la vida de los personajes. El texto literario es el punto de partida de sus obras dramáticas, el autor suele estructurar los dramas en forma de collage con elementos surrealistas o fantásticos. Los personajes se dirigen al público para brindar información y narrar sus experiencias.

En España, Ignacio del Moral es de los primeros en incorporar la temática en obras como Rey negro, La mirada del hombre oscuro. Le siguen autores como David Planell (Bazar), Juan Mayorga (Animales nocturnos) y Fermín Cabal (Maldita coci- 
na). En los años noventa destaca el ámbito catalán con obras como $A$ trenc d'alba, de Ignasi García, Mombasa, de Raimon Ávila, etc. Finalmente, Sergi Belbel, con Forasters, y Josep Pere Peyró, con el montaje A les portes del cel. Esta última obra se distingue por ser un proyecto de intercambio directo o contaminación de dos comunidades; Peyró contó para la creación del texto con la colaboración del dramaturgo marroquí Ahmed Ghazali. El autor ha explorado el juego entre realidad y ficción en Le mouton et la baleine y recoge la herencia de los narradores de historias africanos en Tombuctú. Finalmente, hay que destacar a Carles Batlle por utilizar la temática del "choque de culturas" con un alto componente narrativo en Combat, Les veus de Iambu, Oasi y Temptació.

Lo narrativo forma parte del origen del teatro en cuanto a temas y argumentos desde las tragedias y comedias greco-latinas. García Barrientos (2004: 510) observa también una postura contraria o de rechazo de lo narrativo; el autor se refiere al teatro más rupturista que enriquece el concepto de dramaturgia "abierta" a partir de los años 50: es el caso de Beckett, Ionesco, Pinter, Handke, Müller, etc. Sin embargo, opino que este teatro evoluciona tras las vanguardias narrativas del XX o en sus precedentes (basta citar la experimentación formal del Tristam Shandy, de Sterne, en el siglo XVIII). A partir de los años 20 se produce un cambio en el modo de narrar en novelas como En busca del tiempo perdido, Ulises, La montaña mágica, etc, que insertan en su interior elementos líricos, dramáticos o argumentativos. Por esta razón, Garrido Domínguez (1993: 13) expone la dificultad de ofrecer una definición adecuada del texto narrativo en la contemporaneidad. El ideal romántico y la mezcla de géneros se cumple en el siglo XX y más aún, diría yo, en pleno siglo XXI. La dramaturgia vuelve a los orígenes para enriquecerse con formas narrativas (como el monólogo) o líricas, los géneros se fusionan y contaminan en la actualidad más que nunca. Fruto de esta asimilación son las dramaturgias de Sanchis Sinisterra, además de dos obras destacadas por García Barrientos: Camino de Wolokolamsk, de Heiner Müller, por ser un texto narrativo escrito en verso (aunque el autor añada una nota al final del primer texto que alude a la escenificación) y El sueño de Ginebra, de Juan Mayorga.

Hace dos mil quinientos años Aristóteles definió por primera vez la narración de acciones como un hecho compartido por el género épico y el dramático. La literatura es mímesis de acciones y, secundariamente, mímesis de hombres actuantes; García Barrientos se basa en la fundamental distinción de Aristóteles en la Poética (1448a) para diferenciar los dos modos de imitación: mediata (en la narración) e in-mediata (en lo dramático). El autor (2004: 514) afirma que el modo in-mediato imprime al texto dramático su peculiar estructura con la superposición de dos "subtextos" (diálogo y acotaciones) y esta categoría modal se opone radicalmente a la del texto narrativo. Aunque, hay categorías comunes entre los dos modos -tiempo, distancia, perspectiva y niveles representativos- también se observan oposiciones: el tiempo narrado es pasado y el de la actuación apunta al presente. Por otra parte, la "voz narrativa" es categoría exclusiva de la narración mientras el espacio y el personaje son muy pertinentes en el texto dramático. El espacio teatral puede ser la categoría equivalente a la "voz narrativa" puesto que ambos suponen la puerta de entrada al universo representado.

Esta distinción modal hace que todo texto narrativo necesite de una dramaturgia para su puesta en escena. El primer paso consiste en la fase de análisis del hipotexto y la toma de decisiones, según cada obra; por ejemplo, la narrativa clásica se cons- 
truye en base a un argumento y personajes normalmente bien definidos. En cambio, las vanguardias literarias ofrecen más dificultades a la adaptación teatral en el ámbito de la novela; cuando Sanchis Sinisterra hace una dramaturgia del Ulises, de James Joyce, no lo hace del Ulises completo sino que utiliza solo el capítulo final de la novela porque plantea un soliloquio que es trasladable al monólogo dramático.

Me parece muy útil, en esta fase de análisis, el estudio detallado de Luciano E. García Lorenzo (1970: 445-471) en su pionero trabajo comparativo de la novela Doña Perfecta adaptada al teatro por el propio Pérez Galdós. El autor establece un método de análisis fundamentado en los cinco elementos del texto narrativo y dramático. El original y la versión teatral se desarrollan a través de una acción que mantiene la atención del lector o espectador hasta el último capítulo o escena; esta acción es consecuencia de unas situaciones vividas por los personajes en un tiempo progresivo y en uno o varios espacios, y, por último, el lenguaje es imprescindible para la expresión del escritor. Además los dos géneros pueden contar la misma historia y, por tanto, comparten la misma estructura profunda, que implica contar hechos. Esta metodología, basada en la narratología de Genette (1972, 1983), permite esclarecer de un modo inductivo los rasgos comunes y las diferencias de ambos géneros al preparar la dramaturgia de una novela en particular. Por tanto, al adaptar un texto narrativo conviene analizar los cinco elementos esenciales que lo conforman y que comparte con el texto dramático: la acción, los personajes, el tiempo, el espacio y el lenguaje. Ignacio García May también aconseja investigar la dramaturgia de la época a la que corresponde la novela; estos primeros pasos de análisis del original e investigación del teatro de su tiempo nos sirven para trasladar los códigos de un género a otro y, aunque no sea la única herramienta de trabajo, es una forma viable de hacerlo.

Por otra parte, García Barrientos (2014: 216) se basa en la citada distinción aristotélica sobre los dos modos de imitación para afirmar que la novela y el cine nos introducen en la ficción a través de la instancia mediadora de la voz del narrador y el ojo de la cámara. Por el contrario, el drama no utiliza mediador y la historia es presentada ante los espectadores de forma inmediata (en el aquí y ahora de la representación); destaca que esa inmediatez es la que determina la estructura peculiar de la obra dramática. La diferencia del texto dramático, respecto a los demás géneros literarios, es su destino espectacular. Sin embargo, un texto narrativo se puede convertir en dramático mediante una dramaturgia puesto que "la narrativización del drama es predramática”, en opinión de García Barrientos (2014: 217). El teatro comenzó dramatizando los mitos y, por ello, Aristóteles considera la tragedia como la culminación superadora de la epopeya (narración). El paso del monólogo primigenio al diálogo teatral explica la evolución de lo narrativo a lo dramático (al aumentar el número de actores en las tragedias de Esquilo a Eurípides).

Conviene recapacitar, por tanto, sobre la especificidad del género teatral a partir de las definiciones de Ignacio García May. Según el autor, el teatro (2016: 25) “ “. no es un género literario sino un arte/ lenguaje/ industria de naturaleza mercurial: extraordinariamente difícil de aprender. En dicho arte/lenguaje/industria el texto ocupa lugares muy distintos: puede ser esencial o completamente prescindible".

De aquí se deduce que el texto dramático no es solo un género literario puesto que genera un tipo de espectáculo. El dramaturgo recuerda, a este propósito, que muchos textos literarios, como la novela o el ensayo, están escritos en forma de diálogo o incluyen alguna acotación, pero eso no implica que sean teatro. El Ulises, de Joyce, incluye entre sus páginas pasajes escritos a la manera del teatro: nombre del perso- 
naje a la izquierda de la página, guión, acotación entre paréntesis, texto del diálogo. Por citar otro caso, Misericordia, de Pérez Galdós, está escrita en muchas de sus partes de forma dialogada y con alguna acotación y, sin embargo, eso no la convierte en un texto dramático. Por el contrario, hay dramas sin acotaciones y algunas piezas que aparecen escritas como una sola voz unitaria que solo se fragmentan en diversos personajes al adaptarlas para su puesta en escena.

La concepción actual de drama contiene la estructura clásica "cerrada" y la "abierta"; ambas dramaturgias confirman que el teatro contemporáneo se caracteriza por compartir fronteras, en muchos casos, con la novela. García Barrientos (2014: 211221) plantea nueve tesis que ahondan sobre el papel de la narración en el drama para poner de manifiesto el mestizaje del género dramático actual y su contaminación por la presencia de elementos narrativos. Destaco la tesis cuarta de su argumentación, cuando afirma que el drama se puede contagiar de narración por varias vías y distingue las tres principales: temática, estructural y discursiva. La primera implica la derivación a partir de todo tipo de relato - mito, leyenda, historia, crónicas, Biblia e historia sagrada-, además de la literatura narrativa: cuento, poema épico, novelas. En este caso el material narrativo ha aportado argumentos y fábulas desde Grecia a la actualidad. La narratividad temática ha sido estudiada por Peter Szondi (1956) en el periodo de 1880 a 1950 con la importante aportación de la mediación temática del "yo épico". Por otra parte, Tadeusz Kowzan ofrece, entre otras consideraciones, una panorámica sobre los veintisiete siglos de teatro europeo, insistiendo, en el caso de Francia (1992: 82-147), sobre la derivación temática. La narratividad estructural coincide con la construcción "abierta" en obras como Luces de Bohemia, de Valle-Inclán; García Barrientos (2014: 218) destaca, entre otras, dos obras dramáticas que lindan con el relato: Perder la cabeza y iQue viva Cristo Rey!, de Jaime Chabaud. Finalmente, la narratividad discursiva es la que puede resultar más problemática, si invade la acción dramática o el diálogo. Como conclusión se deduce que esta narratividad es inherente al teatro desde la tragedia, se trata generalmente del relato del mensajero, el coro o de un personaje. De aquí se desprende, por tanto, que existen dramas narrativos o narraciones dramáticas; lo normal es que un modo se subordine al otro, que un drama tenga interpolaciones narrativas (y viceversa), pero el modo dramático debe mantenerse si se hace una dramaturgia. De lo contrario, el espectador abandonará la sala.

La segunda concreción de García May amplía el concepto de inmediatez del teatro que responde a otro tipo de lectura convencional:

Un texto dramático es aquella estructura literaria en la que, de forma voluntaria y consciente, el autor ha incluido una serie de enigmas que habitualmente no son percibidos en la lectura convencional y que se hacen obvios únicamente durante el proceso de la puesta en escena, completando con ello su significado. Corresponde, por tanto, a la puesta en escena, dar respuesta a dichos enigmas.

Esta explicación demuestra que los significados del texto dramático se ponen de relieve en la puesta en escena. El texto dramático se diferencia de los otros géneros literarios por sus rasgos formales y por su naturaleza de proceso semiótico comunicativo. El destino de la obra dramática culmina en la representación ante el público; García Barrientos (2001: 39) establece la interrelación de sus cuatro elementos fundamentales: espacio, tiempo, personajes y público. Además, el teatro suele mantener un discurso constante, el diálogo (aunque hay obras en monólogo o sin palabras), 
mientras la novela o la poesía utilizan también otras formas de discurso. El estudio y reflexión sobre los géneros recorre un largo camino que comienza en Grecia con Platón en aquel pasaje de la República (III: 392a-3995a), en el que se establece, por primera vez, la división tripartita: el ditirambo (habla solo el poeta), el género épico (hablan el poeta y los personajes) y el dramático (hablan solo los personajes).

Garrido Domínguez (1993) insiste, a propósito de la Poética de Aristóteles (1448a, 1449b-1450b), en la distinción entre el género épico y el trágico, a partir de los elementos que conforman a cada uno (los rasgos comunes y los particulares). Quizá lo más destacado sea que en el texto del Estagirita ya se mencionan algunos rasgos que la moderna narratología ha convertido en instrumentos fundamentales de la estructura del texto narrativo. A su vez esta disciplina y su estudio sirve de modelo para analizar no sólo la naturaleza y particularidades de la narrativa, sino que se puede aplicar al análisis del drama. En concreto, la dramatología que utilizo para el análisis es la que construye García Barrientos (1991, 2001, 2004, 2007) a partir de la narratología de Genette $(1972,1983)$. Ambas disciplinas sirven para establecer las convergencias y divergencias entre dramaticidad y narratividad.

En el texto narrativo, el narrador -omnisciente, objetivo o subjetivo- detenta el punto de vista del que observa o cuenta la historia. La comunicación literaria se desarrolla de manera lineal: autor -texto escrito- lector. En cambio, en el teatro la comunicación es circular, ya que se lleva a cabo un proceso dialógico entre el autor (primer emisor), director y actores (también emisores, que a su vez han sido receptores) y una doble recepción: la individual, del texto dramático escrito, y la colectiva, que implica la representación.

El texto que figura a continuación es un fragmento de Para un joven dramaturgo, de Marco Antonio de la Parra, que revela, entre otros aspectos, la diferencia comunicativa de la escritura dramática respecto de los demás géneros (1993:12):

Escribir drama no es una escritura cualquiera. No es tan solo una variante de la li-
teratura ni menos la base única del teatro. (...) Su lenguaje es heredero de la poesía
y de la novela pero su relación con ambas es extraña y equidistante.
Se dice que la relación de la poesía con el tiempo es vertical,
privilegia el instante, carga el lenguaje en síntesis mientras que la novela es hori-
zontal, maneja los antecedentes y aprovecha el análisis.
El teatro es diagonal.
Anuda ambos casos...

Por otra parte, la semiótica del teatro ha mostrado, desde sus fundadores checos en los años treinta, el enfrentamiento entre la concepción literaria o verbal del teatro y la concepción espectacular del mismo; ambos términos se oponen o complementan. Según Veltrusky, el texto dramático predetermina el teatro y es, además, una obra literaria que se realiza en la lectura silenciosa individual. Por el contrario, Zich lo ve como un elemento del espectáculo y niega su existencia poética independiente, según García Barrientos (1991: 33).

Siguiendo las definiciones anteriores, el drama es, en sentido general, teatro y, a la vez, espectáculo. García Barrientos (1991: 121) explica las tres categorías de la representación dramática: el tiempo, el espacio y la propia visión; dicho en otros términos: el drama es algo que vemos o que se representa en un espacio y un tiempo con un punto de vista determinado. La dramatología aborda, por tanto, el estudio de 
toda obra escrita con vistas a la representación (teatral o fílmica). La conclusión a que nos lleva todo esto es que se requieren dos condiciones para la representación: la presencia de actores y espectadores en un mismo espacio y tiempo de representación.

Es preciso, con todo, ahondar un poco más sobre los elementos que configuran el texto dramático y lo diferencian de los otros géneros, específicamente, el narrativo. Hay que aludir, en primer lugar, como se ha dicho, al tiempo y al espacio, que tienen la particularidad de estar desdoblados en el teatro: los de la representación y los de la ficción. Seguidamente, el personaje, que asume el punto de vista o modo de "visión" del dramaturgo; en tercer lugar, la trama (caracterizada por ser sintética); y, por último, el discurso (diálogo). Estos serían los elementos constitutivos del texto dramático desde una perspectiva formal y los que lo diferencian de los demás géneros.

El rasgo diferencial de lo dramático respecto de lo narrativo es la ausencia de la "voz": no existe el "narrador" en dramatología. Las únicas voces en el teatro son las de los personajes que hablan, pero no cuentan, aunque en ocasiones pueden solo contar hablando, según García Barrientos (1991: 23). Por otra parte, el espacio es un constituyente o elemento representativo en el teatro, mientras en la narración no lo es, pues su espacialidad es solo "ficcional" sin pensar en su virtual representación. Jansen (1984: 259) establece un paralelo entre el espacio escénico y el narrador, ya que ambos elementos sirven de punto de acceso al texto dramático y al narrativo. Por tanto, el espacio teatral equivaldría a la voz del narrador en los textos narrativos. La diferencia radica en que los elementos del texto narrativo necesitan la voz del narrador para existir y ser contados; en el teatro esa capacidad la tienen los personajes pero no nos referimos a los personajes del argumento de la obra, sino al hecho de ser visibles en el espacio de la representación dramática. Asimismo la acotación teatral puede tener paralelismo con la descripción en narrativa, aunque la diferencia fundamental es que en el texto narrativo será siempre producida por la "voz" del narrador. Además la acotación teatral es muda e impersonal; este componente de la estructura dramática tienen un peso relativo en el texto dramático porque ha variado según la época, autores y gustos. Las acotaciones no existían casi en la tragedia griega, el teatro isabelino o el siglo de oro español; por el contrario, son muy abundantes en los siglos XIX y XX en textos de Valle-Inclán, Bernard Shaw, O'Neill, etc. La amplitud o no de las acotaciones tiene sentido cuando el autor quiere explicar a un director su idea del espectáculo, como afirma Bobes Naves (1998: 26). Frente a la dramaturgia de la palabra, Acto sin palabras (I y II), de Beckett, o El pupilo quiere ser tutor, de Peter Handke, muestran otro tipo de escritura dramática basada en el gesto; en estos dos casos extremos las acotaciones invaden el texto dramático. Las obras dramáticas también tienen unos límites que marcan el principio y el final de los textos y, en general, de forma diferente a los demás géneros literarios: suelen comenzar por el título $\mathrm{y}$, seguidamente, la relación de personajes o dramatis personae.

El paralelismo entre el espacio narrativo y la acotación escénica se puede establecer en la descripción por parte del autor de los aspectos no verbales del drama. En particular, la localización en el espacio y/o el tiempo, las indicaciones de principio o final de secuencia, las descripciones de lugar al comienzo de cada acto. Sin embargo, la diferencia fundamental es que no existe la mediación de un narrador; por esta razón, niega García Barrientos (2001: 46) la presunta "narratividad" de las acotaciones en base a las diferencias modales y formales de ambos géneros. El autor añade que no se trata de un verdadero discurso como el diálogo y establece la acotación como no-discurso o pura escritura "indecible", basándose en Issacharoff (1993: 
465). Tampoco le parece bien hablar de categorías mixtas o intermedias por la función representativa que comparte el diálogo con la acotación, como propone Bobes Naves (1998: 813). Conforme a su carácter mudo e impersonal, la acotación carece de las funciones expresiva, apelativa y fática y, además, es incompatible con la función poética, en el sentido de Jakobson. La acotación utilitaria cumple lo dicho hasta aquí por García Barrientos, aunque se producen variaciones según la época, el autor, el tipo de discurso dramático, etc. Hay obras con muy pocas acotaciones y diálogos extensos (Benavente) y otras con acotaciones muy extensas con un papel relevante en la fábula, como ocurre en el caso de Valle-Inclán. El problema surge cuando las acotaciones son literarias: en este caso sí adquieren un paralelismo con la narración, ya que surten efecto en la lectura; en cambio la dificultad aparece al traducirlas escénicamente porque su valor literario se pierde. El teatro de Valle-Inclán representa un caso extremo de acotación cargada de valores "literales" -formales, retóricos o poéticos- como afirma García Barrientos (2001: 47).

Finalmente, algunos autores construyen sus obras solo con acotaciones, es el caso citado de Beckett. Otros construyen escenas importantes, como el desenlace, sin diálogo. Bobes Naves (1998: 26) destaca la función de las acotaciones en estos casos con una obra de Valle-Inclán, Ligazón (pieza que forma parte del Retablo de la avaricia, la lujuria y la muerte). La última escena de esta obra se desarrolla solo con elementos no verbales, visuales y acústicos que, representados en el escenario, hacen referencia a las acotaciones escritas y muestran su importancia en el cronotopo espacio-temporal y el desenlace de la acción dramática sin necesidad de lo verbal. Este ejemplo muestra la importancia de la acotación en ciertas estructuras dramáticas que solo ven realizada su expresión con la representación.

Como conclusión se deduce que la crisis de la forma dramática afecta, según Szondi, a los elementos constitutivos del drama: la fábula, el personaje y el diálogo. Jean-Pierre Sarrazac (2013: 74-78) afirma que la evolución dramatúrgica desde finales del XIX preconiza el teatro de Beckett y el de finales del XX. El diálogo se diluye poco a poco frente al monólogo, que tiende a suspender la acción. Esta tendencia -estática o dinámica estática- del discurso hace que los personajes vivan los conflictos de forma larvada e intrapsíquica. El autor destaca a Ibsen, Strindberg y Chéjov como autores que lo anticipan. Los dramas naturalistas muestran el aislamiento de los personajes; también los simbolistas presentan a unos personajes separados del cosmos y ese miedo les dificulta tener cualquier tipo de relación horizontal. En el drama moderno y contemporáneo la relación entre un personaje y otro vuelve a ser más fluida. Sin embargo, Sarrazac (2013: 75) afirma que el personaje más "que replicar a su congénere, se dirige a ese otro para él a priori invisible e inexistente (solo el actor está al corriente de la existencia, de la presencia del público) que es el espectador".

Por otra parte, la acción tradicionalmente se ha estructurado en actos, según la época y estética. A partir del siglo XX, los dramaturgos se liberan de los corsés clasicistas y hay piezas sin actos, fraccionadas en escenas o estructuradas como un collage. Las obras pueden estar o no divididas en partes, actos, jornadas, escenas, no importa el término utilizado; lo imprescindible es que la acción tenga puntos de giro en su evolución dramática, esto es cambios de continuidad espacio-temporales, los cuales han de ser representados en el espacio y tiempo de la representación. Lo importante del texto dramático es su progresión o al menos que algo crezca... En el teatro de Beckett ese clímax no se da porque los personajes son o hacen cada vez menos; en cambio, la angustia o 
el asombro que provocan sí hace crecer algo en el espectador. Por esta razón, la acción tiene dos formas de construcción: cerrada o abierta. La forma cerrada es la conocida desde la Poética de Aristóteles y se rige por la normativa de la unidad de acción y su conexión con las unidades de tiempo y lugar.

Por el contrario, la estructura abierta acoge todas las construcciones que propongan riesgos y opciones que contravengan o se opongan a la cerrada. La crisis de la forma dramática lleva a repensar la acción que toma múltiples formas desde finales del XIX. La abierta permite más libertad y se aproxima a la disposición narrativa frente a la rigidez unitaria de la cerrada. Se admiten los saltos en el tiempo y la variedad de espacios así como aumentar el número de personajes hasta el punto de la aparición de "episódicos", como admite García Barrientos (2001: 77). A continuación la acción dramática es la unidad más afectada en este tipo de estructura, se quiebran en ella los principios de unidad, integridad y jerarquía, es el caso de la antipieza del teatro del absurdo. Los finales pueden ser abiertos o sin un conflicto (en apariencia) como la expectativa de Vladimir y Estragón en Esperando a Godot. Puede no haber un planteamiento inicial o incidente desencadenante determinado en la acción o el innovador planteamiento del teatro "épico" de Brecht, que contraviene la identificación aristotélica y el término catársis de la obra dramática. Por último, la acción trágica deviene en un teatro de lo cotidiano; la escritura dramática contemporánea busca nuevas formas que dinamitan la estructura tradicional del drama y la crisis de la fábula busca una nueva dialéctica entre forma y contenido. Con todo, sigue habiendo autores que presentan historias de personajes (ambiguos y confrontados con una realidad opresora) e historias dentro de historias, donde la exploración de la narratividad es necesaria para que los personajes revelen su intimidad o narren acontecimientos. También se buscan formas de reconstrucción de la experiencia en las que cabe el relato poético, la distorsión del tiempo, el fragmentarismo, lo fantástico dentro de una situación cotidiana, la didascalia del actor puesta en boca del personaje, la experimentación sobre el punto de vista o la perspectiva en la que incluimos el juego entre realidad y ficción, etc. No hay más que aludir, en el panorama actual europeo, a la producción del citado dramaturgo Roland Schimmelpfennig junto a otras muchas propuestas de autores como Fabrice Melquiot, Händl Klaus, Alexei Schipenco, Xavier Durringer; fuera de Europa sobresale Wajdi Mouawad o la nueva dramaturgia mexicana a partir de las incursiones en la adaptación teatral de Luis Mario Moncada y Martín Acosta, en la que sobresalen Jaime Chabaud, Édgar Chías, German Castillo, Rodolfo Obregón, etc. Se deduce que en la actualidad la dramaturgia busca originar un proceso de recepción inédita, una forma inquietante de presentar las historias que haga salir al espectador de la sala lleno de preguntas y perturbado. El drama contemporáneo inserta largos monólogos, relatos, cartas, fragmentos de diarios íntimos, momentos corales y otros materiales heterogéneos. Para Jean-Pierre Sarrazac el diálogo dramático tal como se está gestando es un diálogo mediatizado, el autor lo denomina (2013: 76):

rapsódico en tanto cose juntos -y descose- modos poéticos diferentes (lírico, épico, dramático, argumentativo), incluso refractarios los unos a los otros, y que es él mismo controlado, organizado, mediatizado por un operador (en el sentido mallarmeano) que retoma ciertas características del rapsoda de la Antigüedad: como dice Goethe, "nadie puede tomar la palabra si él (el operador) no se la ha previamente asignado". 
Sarrazac habla de un "sujeto rapsódico" que amplía y flexibiliza al "sujeto épico" de Szondi. El sujeto rapsódico aparece como un sujeto separado, a la vez interior y exterior a la acción, similar a los personajes del Sueño de Strindberg o a los beckettianos. Simultáneamente los personajes están en escena siempre a la escucha del otro y en una relación de interpelación con el espectador. En cambio, aparece una nueva parte, "otro diálogo", que es la voz del rapsoda que se expresa a través de las didascalias y se inmiscuye en los discursos de los personajes, describe, ordena, analiza, se intercala entre sus gestos y voces. Este sujeto rapsódico aporta una riqueza inmensa a los textos y otra dimensión en la escena. Asimismo, me gustaría destacar el trabajo sobre las didascalias en los talleres de dramaturgia de Sanchis Sinisterra, quien denomina dramaturgia actoral al trabajo de improvisación pautada que dirige desde que formó el Teatro Fronterizo. En el Colaboratorio participan actores, directores de escena y dramaturgos; el trabajo se basa en los siguientes parámetros: organicidad/ organización, inminencia (aquí y ahora), imaginación (que se traduzca en conducta que altera al otro, no en fantasía) y multilógica (el teatro utiliza todas ellas, no basta con ser del siglo XXI).

Sanchis Sinisterra denomina polílogos a la combinación dramatúrgica de tres tipos de discurso dramático: diálogo, monólogo y didascalia ajena o propia (inductiva o no). El dramaturgo inventó esta combinación de discursos tras leer La noche árabe, de Schimmelpfennig. La "didascalia del actor puesta en boca del personaje" es una técnica dramatúrgica que introduce, dentro de una escena de conflicto, la descripción o narración de acciones por parte del personaje. En las improvisaciones del Colaboratorio, Sanchis Sinisterra indica una pausa con la señal (dromplin) y el actor elegido debe romper el diálogo para ejecutar la didascalia que inventa. Estas pueden manifestarse de dos maneras: en primer término, la didascalia propia es la descripción propia del actor como personaje y su relación con el espacio, los objetos, etc. En el caso de realizar acciones físicas, el actor puede probar a decir primero y hacer después (o viceversa). Lo más destacado es que su valoración del espacio dibuja poéticamente toda la situación planteada, atrapa al espectador y sirve también para agudizar el conflicto expuesto y sorprender con pensamientos o formas íntimas de ver del personaje. La segunda es la didascalia ajena se trata de la descripción o narración de lo que hace otro actor (el actor A describe lo que hace B y B realiza la acción). Por último, la tercera variante surge en una improvisación y Sanchis Sinisterra la denomina didascalia inductiva, que consiste en la descripción propia o ajena, pero con la particularidad de que el actor recibe o no la didascalia y, por tanto, tiene la libertad de no ejecutar la acción o realizar lo contrario. Estas didascalias, llevadas a cabo en primera o tercera persona, producen un efecto desconcertante en el receptor/espectador, generan otra dimensión y demuestran que el teatro es metateatral por naturaleza.

\section{Obras citadas}

Abuín, Ángel, El narrador en el teatro. La mediación como procedimiento en el discurso teatral del siglo XX, Santiago de Compostela, Universidad de Santiago de Compostela, 1997.

Aristóteles, Horacio (1987), Artes poéticas, versión bilingüe de Aníbal González, Madrid, ediciones Taurus, 1992. 
Batlle i Jordá, Carles, "Drama contemporáneo y choque de culturas (o la dramaturgia del mestizaje)", Jornadas: Teatro y diálogo entre culturas, Murcia, Ayuntamiento de Murcia, 2008, pp. 11-16.

Bobes Naves, María del Carmen (1997), Semiología de la obra dramática, Madrid, Arco/libros.

-, "El diálogo dramático en Yerma", Acotaciones, nº1, Fundamentos, RESAD, julio-diciembre de 1998, pp. 23-41.

Chías, Édgar (2010), Rapsodias para la escena, México, Teatro Colección BicentenarioCentenario.

De la Parra, Marco Antonio (1993), Para un joven dramaturgo (Sobre creatividad y Dramaturgia), Madrid, Teoría Escénica, Colección editada por el Centro Nacional de Nuevas Tendencias Escénicas.

García Barrientos, José Luis, "El teatro posdramático (Entre el oxímoron y la hipérbole)”, La razón pertinaz. Teoría y Teatro actual en español, Artezblai, 2014, pp. 211-263.

-, Cómo se comenta una obra de teatro, Madrid, Síntesis, 2001.

—, "Teatro y narratividad", Arbor CLXXVII, 699-700 (marzo-abril 2004), pp. 509-522.

García Lorenzo, Luciano E., "Sobre la técnica dramática de Galdós: "Doña Perfecta". De la novela a la obra teatral", Revista mensual de Cultura Hispánica, José Antonio Maravall (ed.), Madrid, no 250-252, (octubre 1970-enero-1971), pp. 445-471.

García May, Ignacio, "La dramaturgia de textos no dramáticos", Manual de dramaturgia, Fernando Doménech (ed.), Madrid, Universidad de Salamanca y RESAD, 2016, pp. 25-45.

Garrido Domínguez, Antonio (1993), El texto narrativo, Madrid, Síntesis.

Hugo, Víctor (1827), Manifiesto Romántico, Barcelona, Península, ediciones de Bolsillo, 1971.

Kowzan, Tadeusz (1970), Literatura y espectáculo, Madrid, Taurus, 1992.

Sanchis Sinisterra, José, Dramaturgia de textos narrativos, Guadalajara, Naque, 2003.

Sarrazac, Jean-Pierre, Léxico del drama moderno y contemporáneo, Jean-Pierre Sarrazac (ed.), traducción de Víctor Viviescas y otros, México, D.F., Serie Teoría y Técnica Teatral Paso de Gato, 2013.

—, L'avenir du drame, Circé/Poche, Belfort, Francia, 1999.

—, "El drama en devenir". Apostilla a L'avenir du drame, Cuadernos de Ensayo Teatral, $\mathrm{n}^{\mathrm{0}} 12$, traducción de Víctor Viviescas, México D.F., ediciones y producciones escénicas Paso de Gato, 2009.

Schimmelpfennig, Roland, La mujer de antes y otros textos dramáticos, traducción de Agostina Salvaggio y Milena Neudeck, Buenos Aires-Argentina, ediciones Colihue, 2009.

Szondi, Peter (1956), Teoría del drama moderno (1880-1950). Tentativa sobre lo trágico, traducción de Javier Orduña, Barcelona, Destino, 1994. 